\title{
Caen - Église Saint-Jean
}

$\mathrm{n}^{\circ} 3331$

\section{François Caligny-Delahaye}

\section{(2) OpenEdition \\ 1 Journals}

Édition électronique

URL : http://journals.openedition.org/adlfi/16887

ISSN : 2114-0502

Éditeur

Ministère de la culture

Référence électronique

François Caligny-Delahaye, "Caen - Église Saint-Jean », ADLFI. Archéologie de la France - Informations [En ligne], Basse-Normandie, mis en ligne le 16 mars 2016, consulté le 01 mai 2019. URL : http:// journals.openedition.org/adlfi/16887

Ce document a été généré automatiquement le 1 mai 2019.

(c) Ministère de la Culture et de la Communication, CNRS 


\title{
Caen - Église Saint-Jean
}

$n^{\circ} 3331$

\author{
François Caligny-Delahaye
}

Lien Atlas (MCC) :

http://atlas.patrimoines.culture.fr/atlas/trunk/index.php?

ap_theme=DOM_2.01.02\&ap_bbox=-0.413;49.153;-0.331;49.216

1 L'intervention archéologique menée dans le cadre de l'opération de consolidation engagée au niveau de la travée de la tour-porche de l'église Saint-Jean a permis d'étudier un ensemble exceptionnel de dalles funéraires de la première moitié du xIV ${ }^{e}$ s. Certaines ont révélé un décor gravé très élaboré associant éléments architecturaux, représentations liturgiques et figures symboliques. Toutes les dalles funéraires mises au jour sont utilisées en remploi pour couvrir deux importantes maçonneries de chaînage. En effet, outre la présence de nombreux fragments de plaques funéraires, les dalles complètes ou quasi complètes présentent des indices suggérant qu'elles n'étaient pas destinées à être placées à cet endroit: usure liée à un passage intensif en contradiction avec la localisation actuelle de la dalle ; traces de bûchement aux extrémités entamant le décor.

2 La mise en œuvre des maçonneries de chaînage semble intervenir dans la campagne de reconstruction de la seconde église gothique après le siège anglais de 1417. Cette hypothèse est en effet suggérée par la date la plus récente pour la dalle funéraire en remploi (1344), mais, également, par l'absence d'indice témoignant d'un début d'affaissement de la tour-porche, cet affaissement résultant de l'édification du premier niveau avec le chemisage des piles de la travée.

3 La travée de la tour-porche, entrée principale de l'église, est aménagée peu de temps après l'achèvement des travaux, alors que l'édifice commence à montrer des signes d'affaissement. Les arcades sud et nord de la travée sont en effet fermées par une cloison pourvue, au moins au sud, d'une porte. Il y a ainsi séparation de la travée centrale des deux bas-côtés. D'une certaine façon, cet aménagement permettait de créer une sorte de narthex. 
Plusieurs sépultures en cercueil ont été repérées. Elles sont cependant peu nombreuses (13 sépultures mises au jour dans les trois sondages), mais si dans les sondages sud et nord, le nombre de sépultures pouvait être limité en raison de la présence des maçonneries de chaînage, la mise en évidence d'un remblai fortement remanié dans le sondage est, situé au niveau du vaisseau central et associé à une grande quantité d'ossements erratiques, de réductions et d'un important ossuaire, suggère la présence d'un grand nombre d'inhumations dans ce secteur de l'église.

5 Enfin, l'intervention archéologique a permis de mettre en évidence les premiers vestiges maçonnés pouvant être rattachés à l'église romane édifiée au cours $\mathrm{du} \mathrm{XI}^{\mathrm{e}} \mathrm{s}$., sous forme d'une fondation conservée sous la pile sud-est de la travée.

6 À l'issue de l'opération, les trois sondages ont été rebouchés pour permettre la mise en œuvre des longrines de béton et le forage des micropieux soutenant les étaiements. Une seule dalle funéraire a pu être prélevée pour être prochainement exposée à l'intérieur de l'église après restauration. Les relevés des décors des dalles qui n'ont pas pu être déposées en raison de leur situation, partiellement engagées sous les chemisages des piles gothiques, seront reproduits sur des panneaux d'exposition accompagnés de photographies. Enfin, l'ensemble des sépultures et ossements recueillis pendant l'opération ont été ré-inhumés dans des espaces réservés à cet effet le long des longrines en béton.

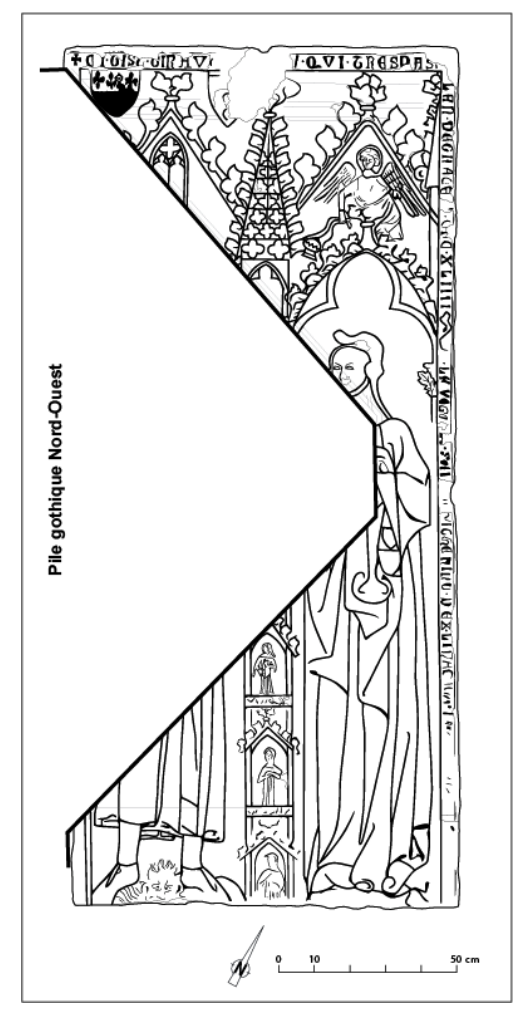

Fig 01

Relevé de la dalle funéraire du couple Giraut (1344)

Dessin : F. Caligny-Delahaye, Inrap 
INDEX

Index géographique : Basse-Normandie, Calvados (14), Caen

Mots-clés : dalle funéraire, décor, maçonnerie, sépulture, ossuaire, fondation

operation Sondage (SD)

Index chronologique : Moyen Âge

\section{AUTEURS}

\section{FRANÇOIS CALIGNY-DELAHAYE}

Inrap 